\title{
Novel Coronavirus Disease (COVID-19): Social Distancing, Isolation and Quarantine are Key Success Factors of Nepal's Public Health Practices or Something Else? Pathak KP, ${ }^{1}$ Gaire $T^{2}{ }^{2}$ Acharya $\mathrm{D}^{3}$
}

\author{
${ }^{1}$ Nepal Open University, Nepal. \\ ${ }^{2}$ Innovative College of Health Science, \\ Kathmandu, Nepal. \\ ${ }^{3}$ Bhairahawa Multiple Campus, \\ Lumbini, Nepal.
}

\section{Corresponding Author}

Tara Gaire

Innovative College of Health Science,

Kathmandu.

E-mail: taragaire33@gmail.com

\section{Citation}

Pathak KP, Gaire T, Acharya D. Novel Coronavirus Disease (COVID-19): Social Distancing, Isolation and Quarantine are Key Success Factors of Nepal's Public Health Practices or Something Else? Kathmandu Univ Med J. 2020;COVID-19 Special Issue 70(2):68-74.

\section{ABSTRACT}

Novel Coronavirus Disease (COVID-19) is an infectious disease similar form of pneumonia/ SARS-CoV-2- impacting deadly globally.

The main objective of this article is to analyze the studies and gather of the current information aimed at COVID-19 and analyze the situation of Nepal. We summarized the published articles from the web pages, Journals, Google search engine.

It is declared as a public health emergency. However, why COVID-19 does not register in developing counties (Nepal) rather than China, Europe and North America it is unknown. Nepal has lower experiences of the COVID-19 where only 49 death cases registered and total cases 19,237 cases throughout the country (till 08/1/2020).

Nepalese health services need to maintain up than today and follow lockdown, isolation, social distance and an advance screening test kit around the country.

\section{KEY WORDS}

COVID-19, Pandemic, Social isolation 


\section{INTRODUCTION}

The given new name COVID-19 is an infectious disease similar form of pneumonia/ SARS-CoV-2 emerging rapidly evolving situation globally, says WHO. ${ }^{1}$ On Feb. 11, 2020, WHO renamed the disease as coronavirus disease 2019 (COVID-19). Now the fear of coronavirus looks pandemic, but its severity is uncertain. The first case of COVID-19 was announced by WHO on 13 December, 2019 inWuhan city, Hubei province of China with unknown etiology. This was declared as a public health emergency by the WHO for every nation while the outbreak of 2019 coronavirus was in January, 2020 and the new cases were 12307 and 259 deaths reported till February1, 2020 including Nepal and other Asian countries. ${ }^{2,3}$ By January 25,2020 , the epidemic had a doubling time of $\approx 6$ days. ${ }^{4}$ The first case (January, 13 2020) was suspected with 32 years' old who was returned from China Wuhan city and since then the government of Nepal started to screen the individuals who came from the aboard especially form the China Wuhan. ${ }^{5}$ Nepal was one of the first nine countries outside of China to report a COVID-19 case.

Historically it has indicated before one hundred years ago (1918 AD), after the end of $1^{\text {st }}$ world war, nearly 50 million people were died worldwide due to Spanish Flu and accordingly 500 million were infected, a world recovering from a global war that had killed 20 million people suddenly had to face even more deadly Flu outbreak. ${ }^{6}$ Similarly, if we do summary of the key characteristics of influenza pandemics from the past one hundred years the world there are seen frequently happening as pandemic and horrible in different time series. The Asian flu H2N2 (19571958) the approximate number of death was 1-2 million and outbreak was from China. Hong Kong flu (1968-1970), H3N2, origin was in China and death was projected 50,0002 million and the Swine flu (H1N1) 2009-2010 was spread in the Mexico and the death number was up to $575,000 .{ }^{7}$ However, Nepal was not registered the death case by Swine Flu then. Another Russian flue (caused by the same H1N1 virus) (1977-78) was estimated about 700,000 people died and by the typical flue were died 400,000 globally., ${ }^{8,9}$ Since the 2009 -2010 such pandemic have been continuing globally throughout global population with associated seasonal outbreaks. ${ }^{10}$ While in 2009, AD. Influenza A H1N1 pandemic: Global infected 700 million -1.4 billion, Global deaths 150,000-600,000, Nepal: Infected 173, Deaths 3. In 2003 AD. SARS outbreak: Global infected $\sim 8,000$, Global deaths-770, Nepal: Infected 0, Deaths 0. ${ }^{11}$

In 1918 AD, the Spanish flu was spread with the main route through the infected travelers. Because of the end of world war $1^{\text {st }}$ the majority population mobility was high on the different sectors like; in traders', laborers, soldiers' sectors and migrants they were travelled from one country to another country. The spread accelerated when the infected soldier came to their family via overcrowded transportation after the end of the WW1. Furthermore, in 1918 AD, only after the first wave of pandemic, nonpharmaceutical intervention was implemented to stop virus transmission like today is doing the same waysClosure of public gathering, bans of public connected places airport, clubs, schools, and promoted to have selfquarantine, self-isolation, and individual/personal health hygiene (cough and sneeze etiquette and use of facemasks etc.) practices and spraying on the residence, community for the disinfection practices. Interventional programs were implemented early and for longer duration had a greater impact in reducing infection and death rates. However, at that time the implemented program was not sufficiently succeed because the NPIs alone could not solve susceptibility infection of virus. The NPIs discontinued inappropriately, and infection was quickly returned to its previous phase. The H1N1 influenza strain emerged by the cause of "Spanish flu pandemic", a disaster that has been called one of the medical catastrophe in history". ${ }^{12}$

All of these deadly and pandemic outbreaks in the past such as flu, SARS and MERS, Hong Kong flue, Asian flu as exhibited almost similar history of disease transmission including COVID-19 today. See foods, Harbor towns, Sea ports, Stations, Ships and Trains transported the infection with easily. Further, poor sanitation, overcrowding, and lack of health services were set off factors. Besides these some were differences between 1918 and 2020 for instance: In 1918 almost the year (1914-1948) was approaching to the end of first-world war. Second, science and technology was as growing phase at that duration and most scientist (physicists) were in the experimentation of immunization and antibiotics to treat secondary bacterial pneumonia were still decades away. Physicists were preoccupied with the structure of atomic particles were not discovered antibiotics because biotechnology was not considered as discipline. Like todays techonology based eras, at that time was not digital medias, social medias and other web internet were not emerging and as not access to the public level to get current information of the pandemic issue that was an another part of impact on mass level (both positive and negative impact) that could deal rapidly as today, 2020. War was helping to the population to be demoralizes to the populations and made weaker human security. Most western countries (European and American) dominated by the colonial powers. Now the situation is not remaining as before, the China and other countries are on the rising their capacity gradually is called "Dawn of Asian Century". Neither there were big institution UN, UNO, WHO, WTO nor governing body in the world in 1918. In spite of, all the progress in science and technology today, what is fundamentally lacking and what the pandemic of the novel coronavirus-19 disarrayed, is the lack of solidarity among nations and dearth of leadership on the world arena., ${ }^{7,13}$

Principle of Prevention and control of any kinds of infectious disease is to "BREAK chain of Infection/ Transmission". How? Chain comprises of Agent (SARS-CoV-2) Host(Human) -Environment and time. It's an epidemiological 
triangle. No one knows whether we are infected with this Virus until we have some signs and symptoms and the test. More than $80 \%$ of the infected may experience symptoms like seasonal flu, cough and mild fever for which majority of us don't go for medical checkup. And 18\% infected never develop symptoms and majority are in incubation period. But they can spread infection unknowingly for those who are vulnerable like children elderly population, sick with chronic diseases, person having lack of immune compromised cases etc.

\section{What are the prevalence rate of COVID-19 on the basis of country?}

It is declared as a public health emergency by the WHO for every nation. (Globally corona virus cases decleared-249,9546, death case- 171,3388, recovered $-658,044$, active cases-2170164 (currently infected patients $-1612526(97 \%)$ in mild condition and 57638 (3\%) in serious or critical cases), closed cases 829382 cases which had an outcome and 658,044 (79\%) cases were recovered or discharged. This COVID -19 affecting 210 countries and 2 international conveyances. The most cases were appeared surprisingly in Europe-105217, North America-45476, Asia15298, South America-4082, Africa-1166, Oceania-88. ${ }^{14}$ The top five countries USA $(42,518)$, spain-21,282, Italy24,114, France-29256, UK-16509 are in top five position. However, Nepal has lower experiences of the COVID-19 where only 41 cases registered, 9 cases active, recovered 4 , and 0 death case throughout the country (till 4/21/2020). ${ }^{15}$

\section{How it can be transmitted?}

Human-to-human transmission is the most serious transmission route of the COVID-19, especially among healthcare workers. ${ }^{16}$ The current consideration is the COVID-19 spread via droplets, direct contact and by coming into contact with contaminated surfaces and objects. When we sneeze, cough or talk, we expel particles in a range of sizes. It remained viable in aerosols for three hours and 72 hours in plastic. ${ }^{17} \mathrm{~A}$ new study in China has been found "the virus in the faces of as many as $53 \%$ of hospitalized patient (still under study). ${ }^{18}$ Therefore, in the case of Nepal need to be careful always with its spreading capacity of this disease because whether we may spread our self of the infection unknowingly to our family and the community or its uncertainty of incubation period. Furthermore, on top of that incubation period (entry of virus into the human body to appearance of first symptoms) of COVID-19 ranged from 2 to 14 days and mostly five days after becoming infected. Some reports suggest that the incubation period may be as long as 19 to 27 days. ${ }^{19}$ However, countries were adapting the universal rules of staying home, social distancing, lock down, using mask, sanitation of hand and band the transportation system worldwide. The south Korea has used testing for the virus aggressively in the large scales to that the infected could be separated form non infected. Thousands of Nepalese have returned home to Nepal from the country India who could be neither be quarantined not tested with the highly approved technology. They are spreading all across the nations (village and towns). Likewise, thousands of Kathmandu living people are moving to the villages where they may be meeting those coming from India and other countries (SAARC countries, UAE, Europen, China, etc.) such situation is quite complicated to apply the safety measures. ${ }^{20}$

The infectivity during the incubation period for the COVID -19 is a big challenge for controlling the disease. Evidence showed that a potential transmission of the COVID-19 during the incubation period, that mean asyamtomatic sysmptoms may transform the virus. ${ }^{21}$ So, Nepalese all were in most vulnerable stage of contamination because country Nepal does not have well sufficiency technologies (digital thermometer) and tools to protect the virus, neither sufficient bed in hospitals nor appropriates facilities with health professionals, it can create epidemic if COVID-19 spreads Nepal. To fight with the COVID-19 Nepal could not have adequate digital thermometer except in Tribhuban Internationals Airport at the early. Similarly, Nepal does not have adequate protective equipment PPE or health care professionals (doctors, medical/para medicals staff and others who involve in treating this virus. Nepalese hospitals were not prepared to treat for the patients with having special ambulances (double cab ambulances) to carry patients to health institutions. Similarly, national public health laboratory, the ministry of health and population lacks reagents to screen the test of the COVID-19. ${ }^{22}$

Although the ministry of health and population of Nepal is working hard to ensure that all passengers who land in Nepal through international flights are carefully screened. Ministry has deployed 13 health workers for screening international passengers at the airport. But this number isn't well enough to screen all the passengers who are entering Nepal by flights. ${ }^{23}$ Nepal government has adapted WHO's country and technical guidance coronavirus disease (COVID -19) as followings: A) Critical preparedness, readiness and response actions for COVID-19, National laboratories B) Risk communication and community engagement C) Early investigation protocols D) Naming the coronavirus disease COVID-19 E) Country level coordination planning and monitoring, Clinical care F) Operational support and logistics G) Virus origin reducing animal human transmission) Humanitarian operations campus and other fragile settings I) Surveillance rapid response teams and case investigation J) Infection protection and control/WASH K) Guidance for schools, workplace and institutions L) Points of entry/mass gatherings M) Health workers. ${ }^{24}$

\section{What can be done?}

Currently, there is no any advance ways to cope this disease infection with-out collective/ joint effort to prevent or control COVID-19. Every citizen of community, government, and stockholders need to understand and follow the rules and regulation rather than ignoring and not applying protective methods what the other worlds are 
adapting. Quarantine and isolation/social isolation is the foremost way to keep ourselves safe as it breaks the chain of infection applying contact tracing-contact identification, contact listing, contact follow-up. ${ }^{25}$

People often interchange the term quarantine and isolation. Isolation and quarantine mean it is public health practices to protect and prevent the public from the exposure of contagious disease. Typically, isolation separates sick people with a contagious disease from people who are not sick. On the other hand, quarantine separates and restricts the movement of people who were exposed to a transmissible disease to see if they become sick. These groups may have been exposed to a disease and do not know it, or they may have the disease but do not show positive signs and symptoms. Thus, quarantine is usually applying for apparently healthy people but are regarded as high risk group (came from infected community/ country/ probably exposed etc.) they may be in incubation period or asymptomatic state but capable of spreading infection in the community unknowingly. Thus, keeping in quarantine must be first line prevention by breaking contamination. Whereas isolation is keeping the infected people separately that they will not spread infection to others. ${ }^{26}$ Further, controlling entry route - people coming from other country should be kept in quarantine before they go to their family. Sheltering in schools nearby by the border with basic facilities. We may keep them in group quarantine under medical supervision and simultaneously orientation and psychosocial counselling to be provided. Sending them in self-quarantine is blunder. That what our government is doing. Self-quarantine is only for those who are already in the community or in their family.

Now experts are suggesting to adapt social distancing at least 3 fits from each other or if possible 6 fit is suggested), use mask properly, social isolation, hand wash, hygiene and cleaning the place where you live. Just using hand sanitizer doesn't protect enough so cleaning surroundings and health promotion activities to boost immunity and stable mental health, drinking warm water more frequently and lemon water etc. can adapt. ${ }^{27}$

Stay in communication and information: in case of any doubt inform appropriate center. Being responsible by own self to the family, community and the world not coming into contact of this, not taking risk behaviors because this deadly virus may easily and sustainably spread its effects in the community that we may not know many things about it.

\section{What was the learning?}

COVID-19 is still evolving, therefore it may be too early to predict the outcome of the current outbreak. However, it is forecasted that COVID-19 could evolve to a low pathogenic but highly transmissible coronavirus, which might return every winter, like the virus that causes seasonal influenza. ${ }^{28}$ At the beginning phase, local outbreaks were ignored, and action was not taken until it was too late to achieve containment. It seemed the major pitfall human being. Uring this time neither we refer for immunization nor medicine because this disease still has showing unknown scenario, if we recognize the nature of disease transmission "the first and the foremost steps to control the infection is stop/delay the infection transmission", as early as possible. ${ }^{29}$ We need a more robust safety net, give workers paid sick leave, health insurance safety net, focus on universal health-care systems, help bolster the economy by supporting consumer spending on the midst of a serious outbreak. Should increase funding for local health departments with ability to prepare for the next pandemic. $^{30}$

No one cannot say the history is always great and it transform many historical lessons for coming days. It is holding the attention that, the approach adopted in 1918 AD., Spanish flu outbreak was almost similar to COVID-19 today? A century before, the scenario was quite different but today we are with better equipment with established system, knowledge, experience, resources and more importantly diagnostic test kit. But, again we have neither vaccine nor medicine to fight virus SARS-CoV-2. Thus, no ways to be safe from the virus by applying discouraging social gathering, stay inside the home, use protective mask, maintain distance appropriately, more frequently hand washing with soap and apply hand sanitizer, after touching and coming from the crowd, diluting household bleach, do apply while buying and selling goods with cash exchanging, alcohol solution, use tissue/newspaper then clean it afterward. ${ }^{31}$

Nepalese peoples are nervous and anxiety has spread more than the virus itself, downfall of economic is being more critical for the miduim class of business/interprenuer are affecting, daily wages workers and pooer peoplese are trying to start ignoreing the rules and going out sides due to hungy dyeing situations. ${ }^{32}$ Domestic violence to the woman and teeangrs issues are arising. ${ }^{33}$ The only one positive improvements has seen on the aspects of environemtental quality. ${ }^{34}$ The river and the air quality has dramatically changing showed by the air quality index. In normal days there used be between 150-180 PM but now it is shown 5-85 PM of the central city areas. ${ }^{35}$

\section{DISCUSSION}

The increasing number of new infection and death toll of this virus has been a major threat and challenge for each and every individual globally. No one knows the natural history of the disease and the true nature of virus perfectly. some recent studies, claimed the presence of COVID-19 in air samples (preliminary data from China, Singapore). to avoid the misleadingness and confusion, and to help scientists and the public with better communication, renaming SARS-CoV-2 as human coronavirus 2019 (HCoV- 
19). Such a name distinguishes the virus from SARS-CoV and keeps it consistent with the WHO name of the disease it causes, COVID-19. ${ }^{36}$

Not only from the experience of Italy, Spain and USA, present outbreak gave lesson - as how world may suffer because of delay preventing intervention and underestimating of disease infections in simple preventive measures. When such level of contagious virus travel via respiratory droplets then it has always been disaster if we don't block / break the travel route of infectious agent urgently. the more humans at any given place and the more they get into contact with each other, the more infections there will be - propagate infection. Along with preventive measures including quarantine and isolation, screening test and contact tracing is must and as soon as possible. otherwise, in such propagated outbreak, it will be too late and we can just wait helplessly until the larger peaks sweep the people. ${ }^{37}$

At last, the group of researchers have been puzzled why COVID-19 does not record developing counties rather than China, Europe and North America? Mostly the lowincome countries in South Asia have not recorded more cases. The hypothesis started to discuss is BCG vaccine did an effectiveness role against COVID-19? It is also published that those countries has still adapted vaccination program of Bacillus Calmette-Guérin (BCG) for T.B. have significantly lower death rate found by the coronavirusalmost six times lower than nations that do not use it, an online based study (Mail Online) revealed..$^{38}$ Some similar findings are publishing online on archive site medRxiv but not in a scientific journal as the research has yet to be peer-reviewed. ${ }^{39}$ It is intriguing thematic issue to see the fact association between BCG use and lower COVID-19 attributable mortality. Even though, we are unable to show about the actions and changes in Nepal after seeing those policies and restrictions in other countries. As well as the public health system in Nepal and that made in significant impact on how COVID changes the healthcare system/ service. In spite of the COVID cases are lower across the Nepal. Off course it takes time to have results.

According to the Ministry of health population Nepal, Nepal has around 2,000 hospitals, of which about 150 are public, and about 4,000 health centres accoros the country. Hospitals across Nepal, both public and private, have 700 ICUs. It is needed ICU beds in single rooms to treat coronavirus patients, which government does not have. There are 155 beds in various hospitals in Kathmandu valley for isolation which is capital city. A lot exceercise fro the government team has trying to sate in the provinces and has studied the situation. This means all other patients must be removed from ICUs even to treat a single coronavirus patient. ${ }^{40}$ Govt. to set up 235 ICU beds amid coronavirus fears. Further, the government meeting has decided to set up 1000 isolation beds, arrange medicines and mobilize specialized health workers to check the spread of the disease. ${ }^{41}$ In comparision, the Italy has avaiblable 3.2 hospital beeds/1000, and 5200 intensive care beds. ${ }^{42}$ The USA has 2.8 bed/1000 people, China has 4.3, south Korea 12.3, Germany $8 .{ }^{42}$ France 6 but Nepal has available only around 0.9 hospitals beds per 1000 people, even if, these countries are struggling with COVID-19. ${ }^{43}$ In contrast, with the others countries of hospitlas and fascilities the nepal's health services capacity can only manage only a few hundreds COVID-19 patients properly. Additionaly, the all hositals' ICU beds are already occupied. Each patient need not less than 10 days approximately 15 days for recover. Neither this algorithms could change nor were able to set Nepal's health system immediately. Thus, this COVID-19 has forced to think for medical community on the separate clinicians providing care system, and algorithm change because COVID-19 is not worse than COVID-19 related pneumonia or influenza. But a Chinese study has shown that the incubation period could be 24 days which was concluded after the examination more that 1000 COVID-19 patients. ${ }^{44}$

Researchers are starting for clinical proof in Australia, Netherlands and Germany that should answer the questions surrounding BCG in the near future. However, it is true that BCG is not itself an antivirus vaccine, but helps to build the body's immunity not just against tuberculosis, but also from viral infections. The trials are being conducted on people at high risk of exposure, primarily health care personnel. On the other hand, public health experts commented that developing countries do not have enough screening equipment/kits for the virus. some developing countries even though they do not have enough screening kits for COVID-19, they still remain low confirmed cases. ${ }^{45}$ Further, there are floating many theories behind this however, more plausible is that people in countries that administer the anti-tuberculosis vaccine (BCG) seem to be less susceptible to COVID-19. Even before this pandemic, there had been epidemiological studies that indicated higher immune levels in people with BCG against communicable diseases, including viral infections. Similarly, the hygiene theory also shows another way to develop the resistance to the new virus because the environment is not sterile as in industrialiser countries. Other scientists have theorized that countries with a high rate of malaria seem to be relatively less affected, and have even proposed chloroquine as a cure..$^{45}$

The another hypothesis is broadly discussing on the basis of spreading disease, these are ecological modeling and mathematical modeling. Ecological modeming argues that transmission of viruses can be affected by the following factors; like altitude, temperature and humidity of environment, population density, age and gender of people. Those people who are residing at higher altitudes may have higher risks of COVID-19 infection because at high altitude, the partial pressure of oxygen declines leading to respiratory stress. Both high temperatures and high humidity can successfully reduce the transmission 
of the virus. The arrival of summer and rainy seasons in the northern hemisphere may therefore effectively reduce the outbreak of COVID-19. In contrast, both cold and dry weather conditions weaken the human immune system, making them susceptible to viral attacks. This model further elaborates if peopayuile stay in for most of the time weather conditions will hardly influence virus transmission due to no chance of contact between people. ${ }^{46,47}$

Likewise, according to mathematical model, disease can extend itself in cities and regions in a narrow eastwest side of the world (about 30-50 $\mathrm{N}^{\prime}$ latitude having temperature between $5-11^{\circ} \mathrm{C}$ and low humidity levels (specific: $3-6 \mathrm{~g} / \mathrm{kg}$ and absolute: $4-7 \mathrm{~g} / \mathrm{m}^{3}$ ). Soon after China, the new epicentres of disease were South Korea, Japan, Iran, and Northern Italy (all roughly along 30-50 $\mathrm{N}^{\prime}$ latitude). Thereafter the disease covered the Northwestern United States, Spain, and France, all along 30-50 $\mathrm{N}^{\prime}$ latitude. However, the virus failed to spread to countries immediately north part of geographical region such as Russia and Mongolia and south of China region. The number of suffered and death patients reported in Southeast Asia is still much less registered record than those in temperate regions. All above mentioning facts shows a strong claim that using on the basis of weather modelling, it is possible to predict countries most likely to be at a higher risk of COVID-19 outbreak in upcoming weeks, allowing for the concentration of public health efforts on surveillance and containment. ${ }^{46}$

To the best of our knowledge, this was the first to predict lower mortality however, due less number of scientific

\section{REFERENCES}

1. Zhu N, Zhang D, Wang W, et al. A novel coronavirus from patients with pneumonia in China, 2019. N Engl J Med. 2020; (published online Jan 24.) DOI:10.1056/NEJMoa2001017

2. World Health Organization. Statement on the second meeting of the International Health Regulations (2005) Emergency Committee regarding the outbreak of novel coronavirus (2019-nCoV).https:// www.who.int/news-room/detail/30-01-2020-statement-on-thesecond-meeting-of-the-international-health-regulations-(2005)emergency-committee-regarding-the-outbreak-of-novel-coronavirus(2019-ncov)

3. World Health Organization. Novel coronavirus (2019-nCoV)Situation report 10-30. 2020; January 2. https://www.who.int/docs/ default-source/coronaviruse/situation-reports/20200130-sitrep-10ncov.pdf?sfvrsn=d0b2e480_2.Date: 2020Date accessed:

4. Wu F, Zhao S, Yu B, Chen YM, Wang W, Song ZG, et al. A new coronavirus associated with human respiratory disease in China. Nature. 2020; doi:10.1038/s41586-020-2008-3.

5. Bastola A, Sah R, Rodriguez-Morales AJ, et al. The first 2019 novel coronavirus case in Nepal. The Lancet Infectious Diseases. 2020; Feb 10. DOI: https://doi.org/10.1016/S1473-3099(20)30067-0

6. Martini M, Gazzaniga V, Bragazzi NL, Barberis I. The Spanish Influenza Pandemic: a lesson from history 100 years after 1918. J Prev Med Hyg. 2019; Mar,29, 60(1): E64. doi: 10.15167/2421-4248/ jpmh2019.60.1.1205.

7. Patrick R, Saunders-Hastings, Krewski D. Reviewing the History of Pandemic Influenza: Understanding Patterns of Emergence and Transmission. Pathogens. 2016; 5(4): 66. Published online; Dec 6. doi: 10.3390/pathogens5040066. publications during Decemebr to July end in Nepalese context our hypothesis may not be generalized when interpreting the results.

\section{CONCLUSION}

Globally hypothesis is floating "why has not hit the country yet, by COVID-19". Thus, it is unanswered: What are the best answers weather may be ecological modeling or mathematical modeling or the association between BCG vaccine and helped fight the COVID-19 Virus or the immunity power is higher with Nepalese by birth or lack of advance screening equipment or something else? Of course, cure and its causative agent are still unknown, require a lot of scientific studies to find the truth. The public health experts warn, Nepalese health services need to maintain up than today and follow lockdown, isolation, social distance and an advance test around the country which is the backbone for the COVID-19 tacckle. The Government of Nepal need to stablish rapidly expand diafnostic services and guidelines for diagnostic services for those who need to be hospitalized, increase measures of social distancing, provide transparent and streamline all communications, reports and data to everyone. ${ }^{48}$ The pandemic of COVID-19 is still developing fluctually. It may become a seasonal pathogen, like influenza, which might return every winter with seasonal outbreaks. Eventhough, COVID-19 is a serious health challenge for Nepal, but so far, the number of deaths has been lower than excepted. ${ }^{49}$

8. Michaelis M, Doerr HW, Cinatl J. Novel swine-origin influenza A virus in humans: another pandemic knocking at the door. Med Microbiol Immunol. 2009; 198: 175-83 (2009). https://doi.org/10.1007/s00430009-0118-5 Online here.

9. Paget J, Spreeuwenberg P, Charu V, et al. Global mortality associated with seasonal influenza epidemics: New burden estimates and predictors from the GLaMOR Project. In J Glob Health. 2019; Dec 9(2): 020421. doi: 10.7189/jogh.09.020421 PMCID: PMC6815659 PMID: 31673337.

10. World Health Organization Influenza Update 260. (accessed on 7 April 2016). Available.online: http://www.who.int/influenza/surveillance monitoring/ updates/2016_04_04_update_GIP_surveillance/en/ Logan M., 2020. Nepali times.Covid-19, Nepal and the hygiene hypothesis. Nepali Times, March 20, 2020; https://www.nepalitimes. com/opinion/covid-19-nepal-and-the-hygiene-hypothesis/

11. Logan M, 2020. Nepali times. Covid-19, Nepal and the hygiene hypothesis. Nepali Times, 2020; March 20. https://www.nepalitimes. com/opinion/covid-19-nepal-and-the-hygiene-hypothesis/

12. Zimmer S, Burke DS Historical perspective-Emergence of influenza a (H1N1) viruses. N Engl J Med. 2009;361:279-85. doi: 10.1056/ NEJMra0904322.

13. Kuszewski K, Brydak L. The epidemiology and history of influenza. Biomed. Pharmacother. 2000; 54:188-95. doi: 10.1016/S07533322(00)89025-3.

14. WORLDOMETER COVID-19 coronavirus pandemic. last updated: April, 21.2020.11:24GMT.https://www.worldometers.info/coronavirus/. 
15. Ministry of Health and Population. Health Emergency Operation Center. Coronavirus disease (COVID-19) outbreak updates and resource materials 2020.

16. Li Q, Guan X, Wu P, et al. Early transmission dynamics in Wuhan, China, of novel coronavirus-infected pneumonia. N Engl J Med. 2020; published online January 29. doi:10.1056/NEJMoa2001316

17. World Health Organization. Modes of transmission of virus causing COVID-19: implications for IPC precaution recommendations. Scientific brief. https://www.who.int/ news-room/commentaries/ detail/modes-of- transmission-of- virus-causing- covid-19implications- for-ipc-precaution-recommendations

18. Wadman M, Couzin-Frankel J, Kaiser J, Matacic C. How does coronavirus kill? Clinicians trace a ferocious rampage through the body, from brain to toes. 2020; Apr. 17, 6:45 PM, https://www. sciencemag.org/news/2020/04/how-does-coronavirus-kill-clinicianstrace-ferocious-rampage-through-body-brain-toes\#

19. Stephen A, Kyra HL, Qifang Bi G, et al. The Incubation Period of Coronavirus Disease 2019 (COVID-19) From Publicly Reported Confirmed Cases: Estimation and Application. Annals of Internal Medicine. 2020; DOI: 10.7326/M20-0504.

20. Shrestha S, 2020. Hundreds of Nepalese stuck at India border amid COVID-19 lockdown. 1 Apr 2020. https://www.aljazeera.com/ news/2020/04/hundreds-nepalese-stuck-india-border-covid-19lockdown-200401031905310.html

21. Li P, Fu Ji-Bo, Li Ke-Feng, Chen Y, Wang Hong-Ling, Liu Lei-Jie, et al. Transmission of COVID-19 in the terminal stage of incubation period: a familial cluster. Int J. of Infect Diseases. 2020; https://doi. org/10.1016/j.ijid.2020.03.027.

22. New spotlight Online. Nepal's Health System Faces Stress To Contain Coronavirus, Death Toll Reaches 304 In China. Feb. 2, 2020, 8:08 a.m. https://www.spotlightnepal.com/2020/02/02/nepals-health-systemfaces-stress-to-contain-coronavirus-death-toll-reaches-304-in-china/

23. Karki B. Nepal Takes Steps to Prepare for COVID-19-Anxieties about the COVID-19 epidemic in Asia are high in Nepal. 2020; March 09. https://thediplomat.com/2020/03/nepal-takes-steps-to-prepare-forcovid-19/

24. World Health Organization. Country and Technical Guidance Coronavirus disease (COVID-19). https://www.who.int/emergencies/ diseases/novel-coronavirus-2019/technical-guidance

25. World Health Organization. Contact tracing, https://www.who.int/ news-room/q-a-detail/contact-tracing, 2017.

26. Center for Diseaase Control and Prevention. What is the difference between quarantine and isolation? 2020; https://www.cdc.gov/ coronavirus/2019-ncov/prevent-getting-sick/social-distancing.html

27. Liverpool L. Coronavirus: What is social distancing and how do you do it? New scientist. 2020;17 March. https://www.newscientist.com/ article/2237664-coronavirus-what-is-social-distancing-and-how-doyou-do-it/

28. Jiang $\mathrm{S}$, Shibo Jiang, Zhengli Shi, et al. A distinct name is needed for the new coronavirus. The Lancet. 2020; https://doi.org/10.1016/ S0140-6736(20)30557-2

29. Pathak KP, Gaire T, Ho MH, Chang HCR. Why has COVID-19 not hit the countries like Nepal yet? Reviews on environmental health. 2020 Sep 2;1.PMID: 32877368 DOI: 10.1515/reveh-2020-0085.

30. Mathis J. America needs to prepare for the next pandemic. The week. 2020; https://theweek.com/articles/900779/america-needsprepare-next-pandemica

31. Center for Diseaase Control and Prevention. How to Protect Yourself and Others. 2020; https://www.cdc.gov/coronavirus/2019-ncov/ prevent-getting-sick/prevention-H.pdf

32. Nepal S. COVID-19: The Street Effects. 2020; April 3, 8:26 p.m. https:// www.spotlightnepal.com/2020/04/03/covid-19-street-effects/

33. United Nations International Children's Emergency Fund- Nepal and Rich M. How teenagers can protect their mental health during coronavirus (COVID-19). 2020; https://www.unicef.org/nepal/howteenagers- can-protect- their-mental- health-during- coronaviruscovid-19
34. Chand PB. How and Why to Prepare for the COVID-19 Pandemic in Nepal. 2020; March 21; http://www.recordnepal.com/categoryexplainers/how-and-why-to-prepare-for-the-covid-19-pandemic-innepal/

35. Baral A. Kathmandu breathes relaxed as lockdown improves airquality. My Rupublca, 2020; Thursday, 23, April, 06:06 PM https:// myrepublica.nagariknetwork.com/news/kathmandu-breathesrelaxed-as-lockdown-improves-air-quality/

36. Gorbalenya AE, Baker SC, Baric RS, et al. Severe acute respiratory syndrome related coronavirus: the species and its viruses-a statement of the Coronavirus Study Group. bioRxiv. 2020; Feb 11. DOI: 2020.02.07.937862.

37. Hamblin J. what you can do right now about the coronavirus. The Atlantic. https://www.theatlantic.com/ health/archive/ 2020/03/ coronavirus-what-you-can-do-help-slow-outbreak/607369/

38. Pinkstone J. Corona virus death rate is SIX TIMES lower in countries that use the century-old tuberculosis BCG vaccine. 2020. https:// www.dailymail.co.uk/sciencetech/article-8197247/Coronavirusdeath- rate-SIX-TIMES-lower- countries-use-BCG vaccine.html? ito=facebook_share_fbia- top\&fbclid $=$ IwAR3BZhynle- GbJ600dCJW9IU6X67LryaxmmRvu- L9HH5tOy3xqIOKbjl

39. Shet A, Ray D, Malavige N, Santosham M, Bar-Zeev N. Differential COVID-19-attributable mortality and BCG vaccine use in countries. https://doi.org/10.1101/2020.04.01.20049478. https://www. medrxiv.org/content/10.1101/2020.04.01.20049478v1

40. Dhakal S. Can Nepal's health system handle COVID-19 sputter? Published: March 12, 2020 7: 59 am On: Kathmandu. https:// thehimalayantimes.com/kathmandu/government-still-not-preparedto-fight-coronavirus-outbreak/

41. My Republika. Govt to set up 235 ICU beds amid coronavirus fears. Published On: March 17, 2020 07:44 AM NPT By: Republica, https:// myrepublica.nagariknetwork.com/news/govt-to-set-up-235-icubeds-amid-coronavirus-fears/

42. Rosenbau L. Facing Covid-19 in Italy - Ethics, Logistics, and Therapeutics on the Epidemic's Front Line. The New Eng J of Med. 2020; DOI: 10.1056/NEJMp2005492.

43. Aleem Z. The US needs a lot more hospital beds to prepare for a spike in coronavirus cases. 2020; Mar 14,5:34pm EDT. https://www.vox. com/science-and-health/2020/3/14/21179714/coronavirus-covid19-hospital-beds-china.

44. Denghui L, Jia D. Coronavirus Study Finds Incubation Period of Up to 24 Days. 2020;Feb 11, 06:05 AM. https://www.caixinglobal. com/2020-02-11/coronavirus-study-finds-incubation-period-of-upto-24-days-101513859.html

45. Pokharel P. Could an anti-TB vaccine be protecting Nepalis? Can't be sure until more tests are done, researchers say. Nepali times. 2020; April 6. https://www.nepalitimes.com/latest/could-an-anti-tbvaccine-be-protecting-nepalis/.

46. Mishra J, Bhusha D, Kumar BR. Coronavirus and its link with climatic, geographical factors.2020; Published on April $8^{\text {th }}$, Wednesday, 4:26 PM. https://english.onlinekhabar.com/coronavirus-and-its-link-withclimatic-geographical-factors.html.

47. Wyns A. How our responses to climate change and the coronavirus are linked. 02 Apr, Climate change researcher, World Health Organization. https://www.weforum.org/agenda/2020/04/climatechange-coronavirus-linked/

48. Chanda PB, How and why to prepare for the COVID-19 Pandemic in Nepal. The record. 2020; March 21. https://www.recordnepal.com/ category-explainers/how-and-why-to-prepare-for-the-covid-19pandemic-in-nepal/

49. Pathak KP. COVID-19 in Nepal: Lower Than Expected Incidence and Mortality. Asia Paci J of Pub Heal. 2020; 01053952094088. doi:10.1177/1010539520940884. 